\title{
Current guidelines in peritoneal dialysis - Part I
} \author{
Group of the Portuguese Society of Nephrology (annex 1) \\ ${ }^{1}$ Department of Nephrology of Curry Cabral Hospital - Centro Hospitalar e Universitário de Lisboa Central, Lisbon, Portugal \\ ${ }^{2}$ Nova Medical School | Faculdade de Ciências Médicas, Universidade Nova de Lisboa, Lisbon, Portugal \\ ${ }^{3}$ Department of Nephrology of Hospital Espírito Santo, Évora, Portugal \\ ${ }^{4}$ Department of Nephrology of Centro Hospitalar de São João, Oporto, Portugal \\ ${ }^{5}$ Department of Nephrology of Centro Hospitalar Universitário do Algarve, Faro, Portugal
}

Ana Carina Ferreira ${ }^{1}{ }^{2}$, Joana Santos ${ }^{3}$, Manuel Amoedo ${ }^{3}$, Ana Oliveira ${ }^{4}$, Rui Silva ${ }^{3}$, Anabela Malho Guedes ${ }^{5}$, on Behalf of the Peritoneal Dialysis' Study

\section{ABSTRACT}

A successful peritoneal dialysis program follows evidence-based practice guidelines. In this first article we review the current guidelines on catheter insertion and on prevention of catheter-related infections, both subjects of extreme importance not only to initiate and also to maintain patients on peritoneal dialysis. The treatment of catheter-related infections is not part of the purpose of this article.

\section{INTRODUCTION}

Peritoneal dialysis (PD) is a dialysis technique used to treat uremic patients since the 1970s. In Portugal, as in many developed countries, this modality is underused compared to hemodialysis ${ }^{1}$, and only $5.8 \%$ of the prevalent dialysis patients are on PD.

The Peritoneal Dialysis Study Group of the Portuguese Society of Nephrology meets annually. The purpose of the annual meeting is to discuss a comprehensive theme to improve PD performance in Portugal. Every year, a different PD unit organizes the annual meeting and in 2017, it was Hospital Garcia de Orta's turn, headed by Fernando Teixeira e Costa and Aura Ramos. The topic chosen was "Guidelines in Peritoneal Dialysis", and the Study Group reviewed the most important ones.

As knowledge of current recommendations, centered on evidence-based practice guidance, is of extreme importance for a successful PD program, we decided to write the different recommendations for adult patients in two review articles. In this first part, we review the current guidelines on catheter insertion and catheter-related infections. In the second part, the guidelines on dialysis prescription, metabolic and cardiovascular management and nutrition will be accessed. We consulted International Society of Peritoneal Dialysis (ISPD) guidelines, UK Renal Association guidelines, European Renal Best Practices (ERBP), Kidney Disease Improving Global Outcomes (KDIGO), and the Portuguese Good Practice Manual in Chronic Dialysis.

\section{CURRENT GUIDELINES ON PERITONEAL DIALYSIS}

\section{Guidelines on Peritoneal access}

The success of peritoneal dialysis as renal replacement therapy depends on a well-functioning peritoneal catheter. The dialysis access is the lifeline of patients and it is fundamental for dialysis adequacy on peritoneal dialysis and hemodialysis.
Catheter-related problems are the second most common cause of switch from PD to hemodialysis (HD) over time $\mathrm{e}^{2-4}$ and remain an important cause of stress and discouragement among patients and peritoneal dialysis staff. Nevertheless, chronic peritoneal dialysis catheters are the most successful of all transcutaneous access devices, with longevity and successful function measured in years rather than days or months ${ }^{5}$.

\section{Peritoneal dialysis catheter types}

In the past, peritoneal dialysis catheters were rigid noncuffed tubes, made of glass or latex and their insertion was performed by percutaneous puncture of the linea alba using a trocar. These catheters only allowed intermittent PD and had to be removed after 24-48 hours. In 1968, Henry Tenckhoff, an American nephrologist, developed the first long-surviving indwelling silicon rubber catheter with 2 Dacron cuffs for insertion by open surgical dissection ${ }^{6}$. Since then, many several PD catheters types have emerged.

The main differences in PD catheter type include the number of cuffs, the shape of subcutaneous tract (straight vs. swan neck), and the shape of intraperitoneal tract (straight vs. coiled) ${ }^{7}$. Most PD catheters are made of soft silicon rubber. Infrequently,-structural changes can occur in silicon catheters with gentamicin cream and mupirocin ointment used for prevention of exit-site infection $(\mathrm{ESi})^{8,9}$. Catheter surface modifications with impregnation with silver ions has not shown a reduction in peritonitis incidence ${ }^{10}$.

Currently, the largest difference between catheters that confers some advantage is the wall thickness. Catheters with thinner walls and larger internal diameter provide a higher rate of dialysate inflow and outflow, allowing faster exchanges ${ }^{5}$. Consequently, it increases peritoneal clearance, maximizing time on peritoneal dialysis and it contributes to a better patients' quality of life. Additionally, the self-locating catheter that includes a small tungsten cylinder at the distal end prevents the catheter floating and migrating ${ }^{11}$. Straight catheters 
are more likely to migrate than swan-neck because of their elastic memory ${ }^{12-14}$. The straight catheters should be used when the exit-site is intended to have a lateral direction, for example in obese patients.

In spite of this, no peritoneal catheter type has proven to be better $^{15}$. Therefore each center should use peritoneal catheters according to their experience (ISPD: Level of Evidence 2C).

\section{Peritoneal dialysis catheter implantation techniques}

There are several techniques used for insertion of peritoneal catheters into the abdominal cavity. These techniques can be divided into blind techniques - modified Seldinger technique; Seldinger technique under fluoroscopic control - and direct visualization techniques - Mini-laparotomy / open surgical dissection; Y-TEC (peritoneoscopy assisted technique); conventional laparoscopy and advanced laparoscopy.

Many different specialists (nephrologists, surgeons and interventional radiologists) have published their experience in placing PD catheters. Insertion of PD catheters by nephrologists has improved the number of patients on peritoneal dialysis ${ }^{16-20}$. The modified Seldinger technique is the technique more accessible to nephrologists and can be performed in ambulatory. The addition of fluoroscopy to the procedure allows real-time confirmation of the catheter position. The open dissection surgical technique or mini-laparotomy, in the hands of experienced nephrologists, is also safe and effective ${ }^{21}$.

In 2014, the guidelines issued by the Society of American Gastrointestinal and Endoscopic Surgeons (SAGES) 22 propose advanced laparoscopy as the gold standard for placing PD catheters. This technique, first described by Crabtree $^{23}$, is defined by rectus sheath tunnelling that ensures a longer track through the muscle and a better anchorage of the catheter; selective omentopexy to minimize omental entrapment and selective adhesiolysis ${ }^{24}$ could be made if necessary. This technique can only be performed by a surgeon ${ }^{25}$ and the patient needs to be submitted to general anesthesia.

Until recently, several studies have demonstrated no definitive superiority between catheter implantation techniques ${ }^{24,26-28}$. However, a meta-analysis just published this year comparing advanced laparoscopy, basic laparoscopy and open insertion shows better results for advanced laparoscopy ${ }^{25}$. Nevertheless, if local expertise for advanced laparoscopy is not available, alternative approaches may be considered and operator expertise should guide the choice of technique (ISPD: Level of Evidence 1B). Although the initial insertion technique can be chosen based on center expertise, it is highly recommended to use laparoscopic technique on revision due to catheter malfunction.

\section{Timing of peritoneal dialysis catheter placement and embedded catheters}

The exact timing for performing a peritoneal access is very difficult to determine.

Too early implantation of an exteriorized PD catheter requires care before starting peritoneal dialysis. The patient or a helper needs to learn routine exit-site care and regular visits to the center are needed for periodic flushing to prevent fibrin plugging. Although this could be an opportunity to initiate the training of PD, it will increase costs and burden to patient.

Most guidelines provide that catheter insertion should be performed at least 2 weeks before starting peritoneal dialysis ((ISPD: Level of Evidence 2B). This allows for a reasonable surgical wound healing and it avoids the need for temporary vascular access for hemodialysis ${ }^{15}$. HD during break-in period should be avoided mainly because of the comorbidities associated with CVC and the possible impact in reducing residual renal function 29 .

In 1993 Moncrief and Popovich published an article on a subcutaneous implantation technique designed to minimize postoperative contamination and decrease the risk of bacterial invasion of the catheter tunnel ${ }^{30}$. In this technique, the catheter is embedded in the subcutaneous tissue until the patient needs to begin dialysis. This technique allows for the timely implantation of PD catheter, comparable to the"maturation time" of arteriovenous fistula (AVF) for hemodialysis ${ }^{31}$. When the patient needs to be started on dialysis, the catheter is easily exteriorized, reducing the risk of a break-in period on $\mathrm{HD}$, and a full dose PD can be immediately initiated.

Although an embedded catheter does not reduce peritonitis or exit-site infection incidence ${ }^{32}$, this technique showed a decrease in mechanical complications such as leaks or hernias ${ }^{33}$ and obviates guessing about the timing of catheter placement relative to the need to start dialysis. The Moncrief-Popovich technique is compared to the AVF of hemodialysis patients ${ }^{30}$. While catheters can be used after having been embedded for over two years, the optimal length is between 6 weeks to 6 months. Some catheters will never be used because of pre-emptive transplantation, patient death or patient choice to start $\mathrm{HD}$ instead of $\mathrm{PD}^{34}$.

\section{Pre and postoperative peritoneal catheter placement care}

Independent of the catheter implantation approach, adherence to a number of universal details is required to ensure a successful long-term peritoneal access ${ }^{35}$. There is a long list of best practices for preoperative preparation for peritoneal catheter implantation and postoperative care but in this review we will only focus on a few specific aspects.

Thus, mostly important, a detailed description of the procedure using clear, simple language understood by the patient. Consequently patients must only sign informed consent if they are fully enlightened about the procedure.

The assessment of previous abdominal surgery is indispensable as is the diagnosis of abdominal wall hernias or stretch marks on physical examination because it can determine implantation technique. We also have to avoid previous scars, abdominal fat wrinkles and even tattoos.

Several preoperative tests are required: complete blood test, coagulation test, electrolytes, glucose, urea and serum creatinine, chest $\mathrm{X}$-ray and electrocardiogram, even when the procedure is performed under local anesthesia. The screening for methicillin-resistant Staphylococcus aureus (MRSA) and nasal carriage of Staphylococcus aureus 
is mandatory and if positive, decolonization should be performed. Nevertheless, all patient should shower with chlorohexidine soap, starting two days before procedure.

Patients need to fast for 8 hours before the surgical procedure. Single intravenous (IV) preoperative dose of prophylactic antibiotic, 1 hour before surgery, should be added (ISPD: Level of Evidence 1A). Studies suggest that prophylactic antibiotic with first-generation cephalosporin or vancomycin effectively reduce early postoperative peritonitis $^{36,37}$. Finally, immediately before the surgical procedure, the exit-site must be marked while the patient is standing.

In catheters primarily externalized it is important to immobilize the catheter on the abdominal wall with medical adhesive ${ }^{38}$. Peritoneal dialysis trained nurses should carry out the dressing after 5 days of catheter placement. Some PD centers authorize embedded catheter dressing to be made in the primary health care center, close to home.

\section{Complications of peritoneal dialysis catheter placement}

Complications following peritoneal dialysis catheter placement are defined as those occurring early ( $<30$ days) or late ( $>30$ days), after surgery ${ }^{39}$ :

\section{Early complications}

- Bowel and other organ perforation;

- Bleeding;

- Catheter dysfunction/outflow failure by kink in the subcutaneous tunnel, clots or fibrin in the catheter, omental wrapping, presence of adhesions in the abdomen, catheter tip migration and others.

- ESi/ tunnel infection;

- Peritonitis;

Late complications

- ESi / tunnel infection;

- Peritonitis;

- Catheter dysfunction/outflow failure by clots or fibrin in the catheter, catheter tip migration or winding in epiploon;

- Leaks;

- Hernias.

\section{Training and audit peritoneal dialysis catheter placement}

Peritoneal dialysis catheter implantation training should be available to all residents who have an interest (ISPD: Level of Evidence $1 \mathrm{C}$ ). The main problem is the time required for physicians to become autonomous since each unit places a small number of catheters and peritoneal dialysis traineeship period in Portugal is only 6-month.

We believe that peritoneal dialysis units should have a nephrologist trained to oversee the peritoneal catheter placement and if a surgeon performs catheter insertion, a peritoneal dialysis nephrologist or nurse must be present in the operating room.
A meeting between team catheter management (nephrologists, surgeons, and nurses), at least once per year, to discuss the results obtained during this year is also suggested (ISPD: Level of Evidence 1B). Several guidelines, namely from ISPD, have reported less than $5 \%$ of exit-site infection and peritonitis, within 2 weeks of catheter insertion; less than $20 \%$ functional catheter problem and at least $80 \%$ of catheters should be patent at 1 year, as a good outcome ${ }^{15}$. It is equally important to examine all post-insertion catheter infection to adjust empirical antibiotic treatment pre-catheter implantation, by identification of the causative organisms.

\section{Catheter related issues}

Catheter malfunction due to catheter tip migration or omental wrapping remains a significant problem in peritoneal dialysis and is one of the main causes of transfer to hemodialysis ${ }^{40-43}$. To treat catheter migration it is possible to use, under fluoroscopic control: a guidewire $^{44}$, a Fogarty catheter ${ }^{45}$ or a trocar manipulation ${ }^{46}$, under sterile conditions. This allows a good initial response but reduced long-term success. Thrombolytics or heparin (2000-3000 units/bag) can also be used to remove fibrin or blood clots ${ }^{47}$.

In our country, vascular access problems in hemodialysis patients are solved in less than 24 hours, as required in the Portuguese 2017 Good Practice Manual in Chronic Dialysis (Manual de Boas Práticas de Diálise Crónica de 2017) ${ }^{48}$. However, in the same document, the timing to peritoneal access dysfunction resolution is not established. This subjective and unclear recommendation often causes a switch to hemodialysis with a central venous catheter (CVC). Nowadays, CVC use in hemodialysis is accepted only as a last resource because of its known complications, such as high incidence of infection or potential vein thrombosis and/or stenosis. We must not allow this to happen in peritoneal dialysis. Complications related to vascular access in HD are quickly solved and patients feel safer on HD, thus leading them to abandon peritoneal dialysis during this time.

Laparoscopy is the best option for catheter malfunction when immediately feasible, minimizing or solving temporary transfer to HD. For this, it is crucial to develop a collaborative approach between nephrologists and surgeons ${ }^{49-51}$. Fluoroscopy-guided management by nephrologists may be a viable option to restore catheter function but malposition recurs and studies do not predict long-term benefit ${ }^{52}$.

\section{Timing of hemodialysis access placement in peritoneal dialysis patients}

On an annual basis, at least $10-20 \%$ of end-stage renal disease patients switch from PD to HD. This conversion should be planned, and it is particularly important to proceed with the creation of a vascular access in these patients ${ }^{53}$. The policy of providing backup fistula in all patients at the time of PD treatment start allowing emergency access for hemodialysis was not successful. Beckingham et al. ${ }^{54}$ showed that in $70 \%$ of PD patients, who required hemodialysis for several reasons, the fistula was not working. The goal is to avoid urgent HD start whenever possible and thus avoiding CVC, as already mentioned.

Considering the above, what is the best timing of vascular access creation in PD patients? Guidelines suggest vascular access creation 
in high-risk failure patients but the criteria for selecting patients are undefined. We suggest preparing a vascular access in patients whose transition to HD is planned, namely in patients with inadequate depuration and/or ultrafiltration, in patients with refractory/recurrent peritonitis when catheter removal can be anticipated or in patients who have a planned major abdominal surgery.

\section{Guidelines for reducing Infections: Exit-site infections and Peritonitis}

\section{Exit-site infections}

Before starting to write about prevention of exit-site infection, the definition of this complication should be addressed. According to the ISPD definition, an ESi is diagnosed in the presence of purulent discharge, independent of the presence / absence of other inflammatory signs ${ }^{55}$. Nevertheless, we can be in the presence of an ESi even without a purulent discharge and, for that reason, a scoring system of the exit-site is available at the same source (Table 1). ESi can be accompanied by tunnel infection, which is defined by the presence of erythema, edema, induration, or tenderness over the subcutaneous pathway. Even so, it can be clinically occult and only shown by sonographic studies ${ }^{55}$.

\section{Table 1}

Exit-site Scoring System

\begin{tabular}{c|c|c|c} 
& 0 points & 1 point & 2 points \\
\hline Swelling & no evidence & $<0.5 \mathrm{~cm}$ & $>0.5 \mathrm{~cm}$ \\
Crust & no evidence & $<0.5 \mathrm{~cm}$ & $>0.5 \mathrm{~cm}$ \\
Redness & no evidence & $<0.5 \mathrm{~cm}$ & $>0.5 \mathrm{~cm}$ \\
\hline Pain & no evidence & Mild & Severe \\
\hline Drainage & no evidence & Serous & Purulent
\end{tabular}

Score of 4 or more points $=$ infection; Purulent drainage alone $=$ infection; Score of $<4$ points may or may not be an infection

The importance of ESi prevention relates to the fact that those infections are a major risk factor for PD-related peritonitis. In Portugal, in 2016, infection was the primary reason for PD patients dropout, accounting for $37 \%$ of technique failure(1). All PD units should have strategies for monitoring their ESi incidence (ISPD Evidence 1C; UK Renal Association Evidence 1B) at least on a yearly basis ${ }^{55,56}$, and PD units should report ESi as number of episodes per year. No minimum target is recommended for ESi and/or tunnel infection.

Moving to the prevention of those episodes, what is the current evidence for the reduction of ESi? We will review 4 items considered critical: nasal carriage of Staphylococcus aureus; catheter placement and design; exit-site care and technique training.

\section{Nasal carriage of Staphylococcus aureus}

According to the Portuguese 2017 Good Practice Manual in Chronic Dialysis, a nasal exudate swab for identification of MRSA carriage and the treatment of the positive cases should be performed, before the implantation of a PD catheter ${ }^{57}$.
While the ISPD guidelines address this issue, there is still discordance in the evidence level: the screening for nasal carriage of $S$. aureus (and not only MRSA) prior to PD catheter insertion is of evidence 2D, and the treatment of the positive cases is $1 \mathrm{~B}$. This is due to the fact that there are no good randomized studies to support the screening of all PD patients, although the efficacy of intranasal mupirocin for the treatment of positive cases has been tested and confirmed in several old prospective studies ${ }^{58,59}$.

\section{Catheter placement and design}

In catheter placement, an important attitude is to define the localization of the exit-site with the patient standing, avoiding the belt area 55,57 .

The implantation technique has no influence on the rate of ESi. With correct training, there is no difference between catheters placed by nephrologists or surgeons, and both percutaneous and surgical approaches (mini-laparotomy or laparoscopy) have similar results. Likewise, no catheter design has been proven to be better for reducing ESi incidence. The existent randomized trials comparing coiled vs. straight PD catheters showed no difference ${ }^{55}$. The comparison between swan-neck and traditional Tenckhoff was performed in two randomized controlled trials in which the ESi incidence was focused, but the results were contradictory ${ }^{60,61}$. The new PD catheters - silver-ion coated and antimicrobial-impregnated-are promising strategies to reduce catheter-related infections and bacterial colonization, yet these catheters are not widely accessible, there is limited familiarity with them and more clinical trials are needed.

The most important approach is the administration of prophylactic perioperative intravenous antibiotics at the time of the catheter placement (ISPD: Evidence 1A; Renal Association: Evidence 1B) ${ }^{55,56}$, covering Gram-positive agents. This attitude is particularly relevant in the reduction of early peritonitis, but has no evidence in the reduction of the rate of $\mathrm{ESi}$, as demonstrated in a recent systematic review ${ }^{62}$.

\section{Exit-site care}

Daily topical antibiotic cream or ointment administration at the exit-site is a recommendation with the level of evidence $1 A^{55,56}$. It should be noted that the application of the topical antibiotic must be on the skin and not the catheter material. The use of mupirocin has proven to be efficient and cost-effective in reducing ESi caused by $S$. aureus. The rate can be reduced towards $72 \%$, as demonstrated by two meta-analyses 63,64 .

Nevertheless, the frequency of use of topical mupirocin is not defined. The minimum should be 3 times a week, though mupirocin resistance was reported with intermittent administration. Therefore, daily administration seems to be appropriate. Other studies showed efficacy of ciprofloxacin otologic solution application at the exit-site, and the efficacy of gentamicin application in order to reduce ESi caused by Pseudomonas species as well as S. aureus infections. Nonetheless, topical gentamicin seems to be associated with an increase of ESi caused by Enterobacteriaceae and non-tuberculous mycobacteria, and should be seen as an alternative agent. A very recent study drew attention to the danger of alternating mupirocin / gentamicin, due to increased risk of fungal peritonitis ${ }^{65}$. 
Turning to cleansing agents, it seems none are superior to soap and water (Evidence $2 \mathrm{~B}$ ) in respect to catheter-related infections ${ }^{55}$. Still, a very recent study revealed that chlorhexidine care at exit-site might be a good option for $S$. aureus and MRSA decolonization, as well as other Gram-negative agents ${ }^{66}$.

\section{Technique training}

Patient training has widely been considered one of the most critical factors for achieving optimal peritoneal dialysis clinical outcomes, including avoidance of peritonitis ${ }^{67}$. In this respect, all patients should have a good initial training, plus domiciliary visits, plus recycling training (Evidence 1C).

Each PD program should have an established curriculum that is followed in teaching the patient the procedure and theory of $P D^{68,69}$ ISPD proposes a syllabus for teaching PD based on a 5-day program of about 3 hours per day ${ }^{70}$.

Nursing staff with appropriate qualifications and experience should conduct PD training (ISPD Evidence $1 \mathrm{C})^{55}$. The nurse selected to provide PD training must have good communication skills, be innovative and consistent, and firmly believe in patient self-care ${ }^{69}$. The ratio of patient to nurse is, ideally, 1:1 (ISPD Opinion) ${ }^{69}$, whenever possible, and for consistency, ideally should be taught by the same nurse throughout the training ${ }^{70}$.

Training may be held before or after PD catheter implantation, in part or in whole, and training sessions should be held on consecutive days ${ }^{70}$. If interruptions are necessary, they shouldn't be superior to 2 days. A large cohort study revealed that the utmost peritonitis rates were in those patients trained within the 10 days after PD catheter insertion when comparing with those trained before catheter inser$\operatorname{tion}^{71}$, despite that commencement of training is recommended between 10 days and 6 weeks and before RRT in order to enable correction of early catheter-related problems without the need for temporary hemodialysis (Renal Association Evidence 1C) (5, $56^{\text {. }}$

Technique training must continue at least until the PD trainer determines that the patient is able to safely perform all required procedures and to recognize contamination and infection. Testing both theoretical concepts and practical skills at the end of training is essential ${ }^{67}$. The syllabus includes a checklist for PD patient assessment and another for PD training ${ }^{70}$, and it is recommended that PD nurses track the number of hours taught each day and record the total teaching hours, as well as the total teaching days, on the checklist ${ }^{70}$.

Patients (and/or carers) should undergo regular revision of their technique at least annually or more frequently if indicated, such as after an episode of PD-related infection or a significant interruption to the patient performing PD (Renal Association Evidence 1C, ISPD recommendation $)^{56,69}$. More frequent retraining should be considered in patients who needed more training sessions at the start of $\mathrm{PD}^{72}$.

Home visits integrate the overall care of PD patients, as home visits provide insight into the way patients adapt and function in their own environment (ISPD opinion) ${ }^{69}$. The timing and frequency of home visits are not established; nonetheless after PD training is completed and patients are started on home PD, a home visit by the PD nurse is often useful in detecting problems with exchange technique, adherence to protocols, and other environmental and behavioral issues which increase the risk of peritonitis ${ }^{69,73,74}$. Thereafter, yearly home visits are suggested ${ }^{74}$.

\section{Peritonitis}

Before approaching peritonitis prevention, let's define peritonitis and explain why it is a major concern of all health professionals working with PD patients.

According to the ISPD, peritonitis should always be diagnosed when at least 2 of the following are present: ${ }^{1}$ clinical features consistent with peritonitis, i.e. abdominal pain and/or cloudy dialysis effluent; ${ }^{2}$ dialysis effluent white cell count $>100 / \mu \mathrm{L}$ or $>0.1 \times 10^{9} / \mathrm{L}$ (after a dwell time of at least 2 hours), with $>50 \%$ polymorphonuclear; and ${ }^{3}$ positive dialysis effluent culture (Evidence $1 \mathrm{C})^{68}$. As with ESi, peritonitis incidence should be monitored at least on a yearly basis $(56,68)$ (ISPD Evidence 1C; Renal Association Evidence 1B) and peritonitis rate should be standardly reported as number of episodes per patient-year and should be no more than 0.5 episodes per year at risk ${ }^{68}$. Although peritonitis rate, in Portugal, is decreasing, in 2016 it still was 0.35 episodes per patient-year ${ }^{1}$, much higher than that reported by some outstanding centers that have an overall peritonitis rate as low as 0.18 to 0.20 episodes per year ${ }^{75,76}$

Peritonitis is a common and serious complication of PD. They are associated with a great morbidity and up to one-third of all PD peritonitis episodes lead to hospitalization ${ }^{77}$. They result in structural and functional alterations of the peritoneal membrane ${ }^{78}$, eventually leading to membrane failure and as mentioned earlier they are a major reason for PD dropout and definitive transfer to hemodialysis ${ }^{1,79}$. In a worst-case scenario they are the direct or major contributing cause of death in around $16 \%$ of PD patients, although less than $5 \%$ of peritonitis episodes result in death ${ }^{79,80}$.

After this background on peritonitis, let's focus on current evidence for its prevention. It can occur at different stages of a PD patient's course: before PD, during PD training, on PD treatment and after peritonitis. Peritoneal dialysis training was already approached in ESi prevention. Now we will review the other three.

\section{Before PD}

In this item we will talk about the prevention measures associated with PD catheter insertion.

As with $\mathrm{ESi}$, there is no difference in the peritonitis rate in patients with catheters placed by laparoscopy/peritoneoscopy versus laparotomy ${ }^{62}$. Also, there are no convincing data that a buried catheter technique lowers peritonitis risk. The catheter design also seems to have no influence on the peritonitis rate: there are no differences in the peritonitis rate between coiled and straight, swan-neck and traditional Tenckhoff or double-cuffed and single-cuffed ${ }^{81}$ PD catheters.

Unlike what happens with ESi, no data exist on the effectiveness of reducing peritonitis rate with the routine screening and 
eradication of Staphylococcus aureus nasal carriage before catheter insertion ${ }^{58}$.

The only proven peritonitis prevention strategy associated with catheter placement is the administration of prophylactic perioperative intravenous antibiotics (ISPD: Evidence 1A; Renal Association: Evidence $1 B)^{55,56,68}$. There is controversy on which is the best antibiotic. In a randomized study vancomycin was superior to cefazolin in reducing the risk for postoperative peritonitis 82 but the use of vancomycin is not widespread due to concern regarding its resistance. Therefore each PD program should determine its own choice of antibiotic for prophylaxis according to their local spectrum of antibiotic resistance ${ }^{68}$.

\section{On PD treatment}

We will highlight three important aspects in peritonitis prevention for patients on PD: PD treatment and environment, exit site care and antibiotic prophylaxis.

\section{$P D$ treatment and environment}

The choice of automated PD (APD) or continuous ambulatory PD (CAPD) regimens in PD patients should not be influenced by a possible effect on peritonitis rates, as studies showed conflicting results. There is also insufficient high-level evidence to support a difference in peritonitis rates when biocompatible fluids are used compared with conventional solutions in PD patients ${ }^{83}$.

The only strategy associated with the technique, with positive results in the reduction of peritonitis rate, is the use of disconnects systems with a "flush before fill" design for CAPD (Evidence 1A). Two systematic reviews concluded that the risk of developing peritonitis was reduced by about one-third with the use of $Y$ systems ${ }^{84,85}$.

The place for the PD exchange should not allow the entry of animals, as exposure to domestic animals is a peritonitis risk factor ${ }^{86}$.

\section{Exit site care}

Daily topical antibiotic cream or ointment administration at the exit-site is a recommendation for peritonitis prevention (Renal Association: Evidence 1A; ISPD: Evidence 1B) ${ }^{55,56,68}$. Such as with ESi, mupirocin has proven to be efficient and cost-effective in reducing peritonitis caused by $S$. aureus; however the reduction of peritonitis is only of $40 \%{ }^{64}$. As stated before daily administration seems to be the best approach. Daily applications of gentamicin cream or of ciprofloxacin otologic solution to the exit site are other options for peritonitis prevention.

As there is a strong association between ESi and subsequent peritonitis(87), early diagnosis of ESi and prompt antibiotic treatment seem important to lower peritonitis risk (ISPD Evidence 1C).

\section{Antibiotic prophylaxis}

Since some invasive procedures are associated with a higher risk of peritonitis, it is recommended that invasive procedures should be accompanied by antibiotic prophylaxis (Renal Association: Evidence 1C; ISPD: Evidence 2C prior to colonoscopy and 2D prior to invasive gynaecologic procedures $)^{56,68}$. One retrospective observational study showed a lower peritonitis rate associated with antibiotic prophylaxis before most endoscopic interventions (colonoscopy, sigmoidoscopy, cystoscopy, hysteroscopy, and hysteroscopy-assisted intrauterine device implantation or removal) ${ }^{88}$. However, the best choice for antibiotic prophylaxis is unknown, as there are no studies analysing this question. Some Portuguese PD units use oral ciprofloxacin and metronidazole in ambulatory patients; in hospitalized patients, IV metronidazole and a cephalosporin. The Renal Association also suggests emptying the abdomen of dialysis fluid for a period commensurate with the procedure ${ }^{56}$. There are also those who recommend prophylactic antifungal administration before gynaecological procedures ${ }^{89}$.

Dental procedures are associated with transient bacteraemia and subsequently peritonitis so prophylactic antibiotic administration (oral amoxicillin) before extensive dental procedures is used in many PD units. Another indication for the use of antibiotic prophylaxis is after wet contamination but the optimal antibiotic regimen has also not been determined.

\section{After peritonitis}

We will discuss the secondary prevention and a continuous quality improvement program.

\section{Secondary prevention}

Oral antifungal prophylaxis should be administrated during an antibiotic course in PD patients to reduce the risk of developing fungal peritonitis (ISPD Evidence 1B; KHA CARI Evidence II) ${ }^{68,89}$, as most fungal peritonitis episodes are preceded by courses of antibiotics. Both fluconazole or nystatin have been used as prophylaxis during antibiotic treatment and showed a significant benefit in lowering fungal peritonitis $^{62,90,91}$, but fluconazole has a worst interactions profile and its increased use is associated with the risk of developing resistance.

\section{Continuous quality improvement program}

Both ISPD and Renal Association recommend that PD units should have a continuous quality improvement program to reduce peritonitis rate (ISPD Evidence 1C; Renal Association Evidence 1B) ${ }^{56,68}$. A multidisciplinary team should constitute this program, and should meet regularly to analyse all PD-related infections (ISPD Evidence $2 C)^{68}$. The objective of this program is to try to identify any problems, to schedule interventions and evaluate their results. These interventions can be at different levels as retraining, reviewing culture methods or changing antibiotic protocols. Preliminary data suggest that the implementation of these programs can reduce peritonitis rates ${ }^{92}$.

\section{CONCLUSIONS}

Table 2 shows the guidelines addressed along this article and the ISPD's level of evidence classification.

The prevention of catheter-related infections is of utmost importance, as this is the first reason for PD dropout in Portugal. Both exit-site infections and peritonitis interconnected and associated with costs and patient morbidity. Although the exit-site care with the daily topical antibiotic cream or ointment is a new recommendation with a level of evidence $1 \mathrm{~A}$, the first line for prevention of a 


\section{Table 2}

Guidelines and ISPD's level of evidence classification on peritoneal access

\begin{tabular}{|c|c|}
\hline ISPD Guideline & Level of evidence \\
\hline \multicolumn{2}{|l|}{ Catheter insertion } \\
\hline Existence of a dedicated team & $1 C$ \\
\hline Implantation 2 weeks before PD start & $2 \mathrm{~B}$ \\
\hline Choice of catheter type according to the center experience & $2 \mathrm{C}$ \\
\hline $\begin{array}{l}\text { Choice of catheter insertion technique according to the center } \\
\text { experience }\end{array}$ & $1 \mathrm{~B}$ \\
\hline Antibiotics prophylaxis at the time of the catheter placement & $1 \mathrm{~A}$ \\
\hline PD catheter implantation training available & $1 C$ \\
\hline Audit yearly PD catheter insertion & $1 \mathrm{~B}$ \\
\hline \multicolumn{2}{|l|}{ PD training } \\
\hline Performed by experienced nursing staff & $1 C$ \\
\hline Performed 10 days -6 weeks before PD start & $1 C$ \\
\hline Initial training, domiciliary visits, yearly recycling training & $1 C$ \\
\hline $\begin{array}{l}\text { Performed after an episode of PD-related infection or a significant } \\
\text { interruption }\end{array}$ & $1 C$ \\
\hline \multicolumn{2}{|l|}{ Exit-site infection (ESi) - prevention } \\
\hline Monitor on a yearly basis & $1 C$ \\
\hline Nasal carriage of S. aureus - screening & $2 \mathrm{D}$ \\
\hline Nasal carriage of $S$. aureus - treatment & $1 \mathrm{~B}$ \\
\hline Antibiotics prophylaxis at the time of the catheter placement & $1 \mathrm{~A}$ \\
\hline Daily topical antibiotic cream or ointment at the exit-site & $1 \mathrm{~A}$ \\
\hline \multicolumn{2}{|l|}{ Peritonitis - prevention } \\
\hline Monitor on a yearly basis & $1 C$ \\
\hline Antibiotics prophylaxis at the time of the catheter placement & $1 \mathrm{~A}$ \\
\hline CAPD - use of disconnects systems with a "flush before fill" design & $1 \mathrm{~A}$ \\
\hline Daily topical antibiotic cream or ointment at the exit-site & $1 \mathrm{~B}$ \\
\hline Early treatment of ESi & $1 C$ \\
\hline Antibiotics prophylaxis prior to colonoscopy / gynaecologic procedure & $2 C / 2 D$ \\
\hline Antifungal prophylaxis during a prolonged antibiotic course & $1 \mathrm{~B}$ \\
\hline
\end{tabular}

catheter-related infection is the administration of prophylactic perioperative intravenous antibiotics at the time of catheter placement. No catheter type or surgical modalities seem to be linked to lower infection rates. The past two decades have seen no development in PD catheters ${ }^{93}$. With the exception of thinner walls and larger internal diameter, allowing faster exchanges and consequently better patient quality of life, there was no other PD catheter type difference. Compared to other techniques (modified Seldinger technique, mini-laparotomy, Y-TEC laparoscopic assisted technique or conventional laparoscopy) advanced laparoscopic offered the best outcomes ${ }^{25}$ in terms of catheter performance (not catheter-related infections), although it can only be performed by a surgeon and patient needs to be submitted to general anesthesia.

According to the "practice makes perfect" theory, experience is frequently associated with better surgical outcomes ${ }^{94}$. Nowadays it is essential to provide a peritoneal catheter-training program. This program will require the grouping of Peritoneal Dialysis Units together with centers with more expertise in PD access, yet even so it will be a long process because of a limited amount of patients on peritoneal dialysis. Lastly, this program must be implemented as part of the Peritoneal Dialysis' Study Group of the Portuguese Nephrology Society.

\section{ANNEX}

\section{Annex 1 - Peritoneal Dialysis' Study Group of the Portuguese Society of Nephrology:} http://www.bbg01.com/cdn/rsc/spnefro/advaccess/175/Nefro331 REVIEWARTICLECurrentguidelinesinperitonealdialysis8211; Partl ANEXO.pdf

\section{References}

1. Relatórios Anuais 2017 [Internet]. SPN. 2017 [cited 18 February 2018].

2. Kolesnyk I, Dekker FW, Boeschoten EW, Krediet RT. Time-dependent reasons for peritoneal dialysis technique failure and mortality. Perit Dial Int. 2010;30(2):170-7.

3. Jaar BG, Plantinga LC, Crews DC, Fink NE, Hebah N, Coresh J, et al. Timing, causes, predictors and prognosis of switching from peritoneal dialysis to hemodialysis: a prospective study. BMC Nephrol. 2009;10:3.

4. Guo A, Mujais S. Patient and technique survival on peritoneal dialysis in the United States: evaluation in large incident cohorts. Kidney Int Suppl. 2003;(88):S3-12.

5. SR A. Chronic peritoneal dialysis catheters: overview of design, placement, and removal procedures. Semin Dial. 2003;16(4):323-34

6. Tenckhoff HCF. Experience with maintenance peritoneal dialysis in the home. Trans Am Soc Artif Intern Organs. 1970;16:90-5

7. Gallieni MGA, Pinerolo C, Cariati M. Type of peritoneal dialysis catheter and outcomes. J Vasc Access. 2015;15(9):S68-72.

8. Khandelwal MBS, Izatt S, Chu M, Vas S, Bargman J, Oreopoulos D. Structural changes in silicon rubber peritoneal dialysis catheters in patients using mupirocin at the exit site. Int J Artif Organs. 2003;26(10):913-7

9. Gardezi AI SK, Foster DM, Astor BC, Chan MR, Waheed S. Erosion of the silicone peritoneal dialysis catheter with the use of gentamicin cream at the exit site. Adv Perit Dial. 2016:32:15-8.

10. Crabtree JHBR, Siddiqi RA, Huen IT, Hadnott LL, Fishman A. The efficacy of silver-ion implanted catheters in reducing peritoneal dialysis-related infections. Perit Dial Int. 2003;23(4):368-74.

11. Di Paolo N, Capotondo L, Sansoni E, Romolini V, Simola M, Gaggiotti E, et al. The self-locating catheter: clinical experience and follow-up. Perit Dial Int. 2004;24(4):359-64.

12. Stegmayr BGWA, Bergström M, Nilsson C, Engman U, Arnerlöv C, Petersen E. A randomized clinical trial comparing the function of straight and coiled Tenckhoff catheters for peritoneal dialysis. Perit Dial Int. 2005;25(1):85-8.

13. Johnson DW WJ, Wiggins KJ, Kirwan R, Griffin A, Preston J, et al. A randomized controlled trial of coiled versus straight swan-neck Tenckhoff catheters in peritoneal dialysis patients. Am J Kidney Dis. 2006;48(5):812-21.

14. Lo WKLS, Li FK, Choy BY, Lam MF, Tse KC et al. A prospective randomized study on three different peritoneal dialysis catheters. Perit Dial Int. 2003;23(2):S127-31.

15. Figueiredo AGB, Jenkins S, Johnson DW, Mactier R, Ramalakshmi S et al. Clinical practice guidelines for peritoneal access. Perit Dial Int. 2010;30(4):424-9.

16. Goh BLGY, Chew SE, Dalimi MS. Does peritoneal dialysis catheter insertion by interventional nephrologists enhance peritoneal dialysis penetration? Semin Dial. 2008;21(6):561-7.

17. Perl JPA, Kandasamy G, McCormick BB, Quinn RR, Jain AK et al. Peritoneal dialysis catheter implantation by nephrologists is associated with higher rates of peritoneal dialysis utilization: a population-based study. Nephrol Dial Transplant. 2015;30(2):301-9.

18. Li PKCK. Importance of peritoneal dialysis catheter insertion by nephrologists: practice makes perfect. Nephrol Dial Transplant. 2009;24(11):3274-6.

19. Zaman F. Peritoneal dialysis catheter placement by nephrologist. Perit Dial Int. 2008;28(2):138-41.

20. Henderson SBE, Levy J. Safety and efficacy of percutaneous insertion of peritoneal dialysis catheters under sedation and local anaesthetic. Nephrol Dial Transplant. 2009;24(11):3499-504.

21. Chow KMSC, Leung CB, Kwan BC, Pang WF, Li PK. Tenckhoff catheter insertion by nephrologists: open dissection technique. Perit Dial Int. 2010;30(5):524-7.

22. Haggerty SRS, Walsh D, Stefanidis D, Price R, Fanelli RD, et al. Guidelines for laparoscopic peritoneal dialysis access surgery. Surg Endosc. 2014;28(11):3016-45

23. Crabtree JHFA. A laparoscopic method for optimal peritoneal dialysis access. Am Surg. 2005;71(2):135-43.

24. Jwo SCCK, Lee CC, Chen HY. Prospective randomized study for comparison of open surgery with laparoscopic-assisted placement of Tenckhoff peritoneal dialysis catheter-a single center experience and literature review. J Surg Res. 2010;159:489-96.

25. Shrestha BMSD, Kumar A, Shrestha A, Boyes SA, Wilkie ME. Advanced laparoscopic peritoneal dialysis catheter insertion: systematic review and meta-analysis. Perit Dial Int. 2018;38(3):163-71.

26. Strippoli GFTA, Johnson D, Schena FP, Craig JC. Catheter type, placement and insertion techniques for preventing peritonitis in peritoneal dialysis patients. Cochrane Database Syst Rev. 2014;18(4):CD004680.

27. Boujelbane LFN, Chapla K, Melnick D, Redfield RR, Waheed S, et al. Percutaneous versus surgical insertion of PD catheters in dialysis patients: a meta-analysis. J Vasc Access. 2015;16(6):498-505.

28. Tullavardhana T AP, Ungkitphaiboon W, Songtish D. Surgical versus percutaneous techniques for peritoneal dialysis catheter placement: A meta-analysis of the outcomes. Ann Med Surg (Lond). 2016;10:11-8

29. Kim DJ PJ, Huh W, Kim YG, Oh HY. The effect of hemodialysis during break-in period on residual renal function in CAPD patients. Perit Dial Int. 2000;20(6):784-5.

30. Moncrief JW PR, Broadrick $\sqcup$, He ZZ, Simmons EE, Tate RA. The Moncrief-Popovich catheter. A new peritoneal access technique for patients on peritoneal dialysis. ASAIO J. 1993;39:162-65.

31. MK D. Moncrief-Popovich catheter and implantation technique: the AV fistula of peritoneal dialysis. Adv Ren Replace Ther. 2002;9(2):116-24. 
32. Danielsson A BL, Tranaeus A, Hylander B. A prospective randomized study of the effect of a subcutaneously "buried" peritoneal dialysis catheter technique versus standard technique on the incidence of peritonitis and exit-site infection. Perit Dial Int. 2002;22(2):211-9.

33. Brum S RA, Rocha S, Carvalho MJ, Nogueira C, Magalhães C, et al. Moncrief-Popovich technique is an advantageous method of peritoneal dialysis catheter implantation. Nephrol Dial Transplant. 2010;25(9):3070-5.

34. McCormick BB BP, Knoll G, Yelle JD, Page D, Biyani M, Lavoie S. Use of the embedded peritoneal dialysis catheter: experience and results from a North American Center. Kidney Int Suppl. 2006;103:S38-43.

35. Crabtree JH CK. Peritoneal Dialysis Catheter Insertion. Semin Nephrol. 2017;37(1):17-29.

36. Strippoli GF TA, Johnson D, Schena FP, Craig JC. Antimicrobial agents to prevent peritonitis in peritoneal dialysis: a systematic review of randomized controlled trials. Am J Kidney Dis. 2004;44(4):591-603

37. Gadallah MF RG, Mignone J, Patel D, Mitchell L, Tatro S. Role of preoperative antibiotic prophylaxis in preventing postoperative peritonitis in newly placed peritoneal dialysis catheters. Am J Kidney Dis. 2000;36(5):1014-9.

38. Daugirdas JT BP, Ing TS. Handbook of dialysis. 5 ed2014

39. Peppelenbosch A vKW, Bouvy ND, van der Sande FM, Tordoir JH. Peritoneal dialysis catheter placement technique and complications. NDT Plus. 2008;1(4):iv23-iv8.

40. Mujais S SK. Peritoneal dialysis in the US: evaluation of outcomes in contemporary cohorts. Kidney Int Suppl. 2006;103:S21-S6.

41. Descoeudres B KM, Garzoni D, Wolff T, Steiger J, Schaub S, Mayr M. Contribution of early failure to outcome on peritoneal dialysis. Perit Dial Int. 2008;28(3):259-67.

42. Rodrigues AS MC, Silva F, Fonseca I, Nogueira C, Santos J, Silva AS, Cabrita A. Long-term peritoneal dialysis experience in Portugal. Int J Artif Organs. 2006;29(12):1109-16.

43. Schaubel DE BP, Fenton SS. Trends in CAPD technique failure: Canada, 1981-1997. Perit Dial Int. 2001;21(4):365-71

44. Kwon YH KS, Oh JH, Jeong KH, Lee TW. Fluoroscopic guide wire manipulation of malfunctioning peritoneal dialysis catheters initially placed by interventional radiologists. J Vasc Interv Radiol. 2014;25(6):904-10

45. Gadallah MF AN, Arumugam R, Moles K. Role of Fogarty catheter manipulation in management of migrated, nonfunctional peritoneal dialysis catheters. Am J Kidney Dis. 2000;35(2):301-5.

46. Simons ME PG, Voros M, Vanderburgh LC, Rao PS, Oreopoulos DG. Fluoroscopically-guided manipulation of malfunctioning peritoneal dialysis catheters. Perit Dial Int. 1999;19(6):544-9.

47. Zorzanello MM FW, Prowant BE. Use of tissue plasminogen activator in peritoneal dialysis catheters: a literature review and one center's experience. Nephrol Nurs J. 2004:31(5):534-7.

48. http://ordemdosmedicos.pt/wp-content/uploads/2017/09/Boas_Praticas_de_Dialise Cr\%C3\%B3nica_OM_2017.pdf.

49. Brandt CP RE. Use of laparoscopy in the management of malfunctioning peritoneal dialysis catheters. Adv Perit Dial. 1996;12:223-6.

50. Jønler M LL, Kyrval H. Laparoscopic correction and fixation of displaced peritoneal dialysis catheters. Int Urol Nephrol. 2003;35(1):85-6.

51. Ma TK CK, Kwan BC, Ng JK, Choy AS et al. Peritoneal Dialysis Catheter Revision and Replacement by Nephrologist for Peritoneal Dialysis Catheter Malfunction. Nephron. 2018;138(3):214-9.

52. Moss JS MS, Newman GE, Dunnick NR, Vernon WB, Schwab SJ. Malpositioned peritoneal dialysis catheters: a critical reappraisal of correction by stiff-wire manipulation. Am J Kidney Dis. 1990;15(4):305-8.

53. Chiarelli G1 BM, Cozzolino M, Singh S, Kiaii M, Taylor P et al. Vascular access planning in perito neal dialysis patients. Perit Dial Int. 2008;28(6):585-90.

54. Beckingham IJ ORJ, Bishop MC, Blamey RW. Are backup arteriovenous fistulae necessary for patients on continuous ambulatory peritoneal dialysis? Lancet. 1993;341(8857):1384-6.

55. Szeto CC, Li PK, Johnson DW, Bernardini J, Dong J, Figueiredo AE, et al. ISPD Catheter-Related Infection Recommendations: 2017 Update. Perit Dial Int. 2017;37(2):141-54.

56. Woodrow G, Fan SL, Reid C, Denning J, Pyrah AN. Renal Association Clinical Practice Guideline on peritoneal dialysis in adults and children. BMC Nephrol. 2017;18(1):333.

57. Manual de Boas Práticas de Diálise Crónica da Ordem dos Médicos, (2017).

58. Nasal mupirocin prevents Staphylococcus aureus exit-site infection during peritoneal dialysis. Mupirocin Study Group. J Am Soc Nephrol. 1996;7(11):2403-8.

59. Perez-Fontan M, Rosales M, Rodriguez-Carmona A, Moncalian J, Fernandez-Rivera C, Cao M, et al. Treatment of Staphylococcus aureus nasal carriers in CAPD with mupirocin. Adv Perit Dial. 1992;8:242-5.

60. Li CL, Cui TG, Gan HB, Cheung K, Lio WI, Kuok UI. A randomized trial comparing conventional swan-neck straight-tip catheters to straight-tip catheters with an artificial subcutaneous swan neck. Perit Dial Int. 2009;29(3):278-84.

61. Xie JY, Chen N, Ren H, Huang XM, Zhu P. Prospective studies on applications of a two-cuff Swan neck catheter and a Tenckhoff catheter to Chinese CAPD patients. Clin Nephrol. 2009;72(5):373$-9$.

62. Strippoli GF, Tong A, Johnson D, Schena FP, Craig JC. Antimicrobial agents to prevent peritonitis in peritoneal dialysis: a systematic review of randomized controlled trials. Am J Kidney Dis. 2004:44(4):591-603.

63. Tacconelli E, Carmeli Y, Aizer A, Ferreira G, Foreman MG, D’Agata EM. Mupirocin prophylaxis to prevent Staphylococcus aureus infection in patients undergoing dialysis: a meta-analysis. Clin Infect Dis. 2003;37(12):1629-38

64. Xu G, Tu W, Xu C. Mupirocin for preventing exit-site infection and peritonitis in patients undergoing peritoneal dialysis. Nephrol Dial Transplant. 2010;25(2):587-92.

65. Wong PN, Tong GM, Wong YY, Lo KY, Chan SF, Lo MW, et al. Alternating Mupirocin/Gentamicin is Associated with Increased Risk of Fungal Peritonitis as Compared with Gentamicin Alone - Results of a Randomized Open-Label Controlled Trial. Perit Dial Int. 2016;36(3):340-6.
66. Wang HH, Hung SY, Chang MY, Lee YC, Lin HF, Lin TM, et al. Bacterial colonization patterns in daily chlorhexidine care at the exit site in peritoneal dialysis patients-A prospective, randomized controlled trial. PLoS One. 2017;12(10):e0184859.

67. Zhang L, Hawley CM, Johnson DW. Focus on peritoneal dialysis training: working to decrease peritonitis rates. Nephrol Dial Transplant. 2016;31(2):214-22.

68. Li PK, Szeto CC, Piraino B, de Arteaga J, Fan S, Figueiredo AE, et al. ISPD Peritonitis Recommendations: 2016 Update on Prevention and Treatment. Perit Dial Int. 2016;36(5):481-508.

69. Bernardini J, Price V, Figueiredo A, International Society for Peritoneal Dialysis Nursing Liaison C. Peritoneal dialysis patient training, 2006. Perit Dial Int. 2006;26(6):625-32.

70. Figueiredo AE, Bernardini J, Bowes E, Hiramatsu M, Price V, Su C, et al. A Syllabus for Teaching Peritoneal Dialysis to Patients and Caregivers. Perit Dial Int. 2016;36(6):592-605.

71. Figueiredo AE, Moraes TP, Bernardini J, Poli-de-Figueiredo CE, Barretti P, Olandoski M, et al. Impact of patient training patterns on peritonitis rates in a large national cohort study. Nephrol Dial Transplant. 2015;30(1):137-42.

72. Barone RJ, Campora MI, Gimenez NS, Ramirez L, Santopietro M, Panese SA. The importance of the Patient's training in chronic peritoneal dialysis and peritonitis. Adv Perit Dial. 2011;27:97-100.

73. Bernardini J, Dacko C. A survey of home visits at peritoneal dialysis centers in the United States. Perit Dial Int. 1998;18(5):528-31.

74. Firanek CA, Sloand JA, Todd LB. Training patients for automated peritoneal dialysis: A survey of practices in six successful centers in the United States. Nephrol Nurs J. 2013;40(6):481-91.

75. Fang W, Ni Z, Qian J. Key factors for a high-quality peritoneal dialysis program-the role of the PD team and continuous quality improvement. Perit Dial Int. 2014;34 Suppl 2:S35-42.

76. Nishina M, Yanagi H, Kakuta T, Endoh M, Fukagawa M, Takagi A. A 10-year retrospective cohort study on the risk factors for peritoneal dialysis-related peritonitis: a single-center study at Tokai University Hospital. Clin Exp Nephrol. 2014;18(4):649-54.

77. Fried L, Abidi S, Bernardini J, Johnston JR, Piraino B. Hospitalization in peritoneal dialysis patients. Am J Kidney Dis. 1999;33(5):927-33.

78. van Esch S, Struijk DG, Krediet RT. The Natural Time Course of Membrane Alterations During Peritoneal Dialysis Is Partly Altered by Peritonitis. Perit Dial Int. 2016;36(4):448-56.

79. Ghali JR, Bannister KM, Brown FG, Rosman JB, Wiggins KJ, Johnson DW, et al. Microbiology and outcomes of peritonitis in Australian peritoneal dialysis patients. Perit Dial Int. 2011;31(6):651-62.

80. Mujais S. Microbiology and outcomes of peritonitis in North America. Kidney Int Suppl. 2006(103):S55-62

81. Eklund B, Honkanen E, Kyllonen L, Salmela K, Kala AR. Peritoneal dialysis access: prospective randomized comparison of single-cuff and double-cuff straight Tenckhoff catheters. Nephrol Dial Transplant. 1997;12(12):2664-6.

82. Gadallah MF, Ramdeen G, Mignone J, Patel D, Mitchell L, Tatro S. Role of preoperative antibiotic prophylaxis in preventing postoperative peritonitis in newly placed peritoneal dialysis catheters. Am J Kidney Dis. 2000;36(5):1014-9.

83. Cho Y, Johnson DW, Badve SV, Craig JC, Strippoli GF, Wiggins KJ. The impact of neutral-pH peritoneal dialysates with reduced glucose degradation products on clinical outcomes in peritoneal dialysis patients. Kidney Int. 2013;84(5):969-79.

84. Strippoli GF, Tong A, Johnson D, Schena FP, Craig JC. Catheter-related interventions to prevent peritonitis in peritoneal dialysis: a systematic review of randomized, controlled trials. J Am Soc Nephrol. 2004:15(10):2735-46.

85. Daly C, Cody JD, Khan I, Rabindranath KS, Vale L, Wallace SA. Double bag or Y-set versus standard transfer systems for continuous ambulatory peritoneal dialysis in end-stage kidney disease. Cochrane Database Syst Rev. 2014(8):CD003078.

86. Broughton A, Verger C, Goffin E. Pets-related peritonitis in peritoneal dialysis: companion animals or trojan horses? Semin Dial. 2010;23(3):306-16.

87. van Diepen AT, Tomlinson GA, Jassal SV. The association between exit site infection and subsequent peritonitis among peritoneal dialysis patients. Clin J Am Soc Nephrol. 2012;7(8):1266-71.

88. Wu HH, Li IJ, Weng CH, Lee CC, Chen YC, Chang MY, et al. Prophylactic antibiotics for endoscopy-associated peritonitis in peritoneal dialysis patients. PLoS One. 2013;8(8):e71532.

89. Walker A, Bannister K, George C, Mudge D, Yehia M, Lonergan M, et al. KHA-CARI Guideline: peritonitis treatment and prophylaxis. Nephrology (Carlton). 2014;19(2):69-71.

90. Restrepo C, Chacon J, Manjarres G. Fungal peritonitis in peritoneal dialysis patients: successful prophylaxis with fluconazole, as demonstrated by prospective randomized control trial. Perit Dial Int. 2010;30(6):619-25

91. Lo WK, Chan CY, Cheng SW, Poon JF, Chan DT, Cheng IK. A prospective randomized control study of oral nystatin prophylaxis for Candida peritonitis complicating continuous ambulatory peritoneal dialysis. Am J Kidney Dis. 1996;28(4):549-52.

92. Wang J, Zhang H, Liu J, Zhang K, Yi B, Liu Y, et al. Implementation of a continuous quality improvement program reduces the occurrence of peritonitis in PD. Ren Fail. 2014;36(7):1029-32.

93. JH C. Building Our Future to Provide the Most Optimal Peritoneal Access Through Surgeon Training Programs and Medical Device Development. Perit Dial Int. 2018:38(3):161-2.

94. Kinoshita Y ST, Yasunaga $H$, Matsui $H$, Ishikawa A, Fujimura T et al. Hosital-volume effects on perioperative outcomes in peritoneal dialysis catheter implantation: analysis of 2505 cases. Perit Dial Int. 2018.

\section{Correspondence to:}

Ana Carina Ferreira, MD

Rua da Beneficência, nำ8, 1069-166, Lisboa, Portugal

E-mail: a.carina.costa.ferreira@gmail.com 